\title{
Strategic Human Resource Practices and Employee's Engagement: Evidence from Jordanian Commercial Banks
}

\author{
Ayman Suleiman Jarrar
}

\section{ABSTRACT}

\begin{abstract}
The study investigates the impact of strategic human resource practices on employee engagement and the mediating role of transformational leadership in the context of Jordanian 13 commercial banks. This study will be a pioneer study in Jordan that will analyze the same topic up to the researcher's boundaries of knowledge. The research population consists of all the 13 Jordanian commercial banks, as per the website for the Association of Banks in Jordan (Association of Banks in Jordan, 2020). The number of workers in the banks is estimated at $\mathbf{1 5 , 5 5 3}$. The researcher will use the proportional stratified random sample technique. According to the population size $(15,553)$ divided on the selected banks and depending on Sekaran`s table (Sekaran \& Bougie, 2016, 263), the sample size was determined based on the employees` number in each selected bank with an acceptable margin of error $5 \%$. The sample size is 375 . The unit of analysis in this study will be the employee working in Jordanian commercial banks. The study results confirm the impact of HRM on employee's commitment and the partial mediating role of transformational leadership.
\end{abstract}

Keywords: Banks, commitment, HR, Jordan, Transformational leadership.
Submitted : November 09, 2021

Published : January 22, 2022

ISSN: $2507-1076$

DOI: $10.24018 /$ ejbmr.2022.7.1.1163

Ayman Jarrar*

World Islamic Sciences and Education

University, Jordan.

(e-mail: ajarrar@firstnutrition.com)

*Corresponding Author

\section{INTRODUCTION}

What role does human capital play in creating and strengthening this relationship, as well as transformative leadership? The study's primary purpose is to look into the impact of strategic human resource practices on employee engagement. This study will be a pioneer study in Jordan that will analyze the same topic up to the researcher's boundaries of knowledge. Therefore, it will help future research enrich Jordan's academic work by serving as a baseline for their work. It will also contribute to the literature on strategic management and HR management by clarifying whether strategic HR practices are critical predictors of employee engagement in firms.

Human Resource (HR) practices are critical to the growth of any firm (Loshali \& Krishnan, 2013). Staff recruitment, selection processes, training, and performance review are all part of these HR activities. As a result, all organizations must focus on planned HR (Alzyoud, 2018). Of course, external elements, like technology and money, have an essential role in working capacity and human resource management and HR strategies. Nonetheless, external influences and HR policies boost employee engagement. As a result of this involvement, job performance and happiness improve (Raina $\&$ Kalse, 2018). Furthermore, the retention of engaged employees is critical to the quality of work and the company's success (Alzyoud, 2018; Oluwatayo \& Adetoro, 2020).

Mental absorptions are revealed via job involvement. It also demonstrates the benefits of administrative work (Loshali \& Krishnan, 2013). Moral interactions, which involve emotional containment, can be considered part of the elaboration in such processes (Alzyoud, 2018). As a result, workplace engagement can effectively channel a worker's efforts toward success and efficiency (Oluwatayo \& Adetoro, 2020)

Worker attitudes about their career, tolerant outcomes, commitment levels, and emotional values associated with the behaviors are socio-demographic and cultural elements that influence job engagement (Oluwatayo \& Adetoro, 2020). HR standardized quality education, career planning, marketoriented training, performance evaluation, and worker empowerment (Raina \& Kalse, 2018). However, some HR strategies, such as performance freedom, engagement, teamwork, and remuneration, enable the placement of competent and motivated personnel (Alzyoud, 2018). Nonetheless, empowerment, training, and rewards are three critical HR policies that help firms increase their performance, quality, and productivity (Chaudhry \& Joshi, 2017).

In firms, affirmative $\mathrm{HR}$ practices create a constructive resonance between managers and employees. HR strategy is an excellent tool. It is vital in the improvement of many HR procedures (Singh et al., 2020). The main determinants of employee performance and engagement at work are an inadequate salary structure, a lack of opportunities, weak incentive schemes for excellent job performance, a promotion code based on seniority rather than actual performance, delays in promotion, non-existent compensation modules, punitive treatment, and the absence of motivational strategies (Lamond \& Zheng, 2010; Loshali \& Krishnan, 2013). 
With a growing population and more intense competition in the twenty-first century, how a company is managed - in terms of transactional and transformational leadership - is critical in improving firm success. Human resources, including strategic management approaches, might be the key to a company's success in the current economic period. As in the past, the human resources department is not the only source of assistance (Alzyoud, 2018). However, adequately handled strategic human resource management is the key to business success in the present day. This study examines the concept of transformational leadership concerning strategic HR management to improve an organization's productivity (Oluwatayo \& Adetoro, 2020).

Jordanian commercial banks are one of the country's key economic drivers; they act as money multipliers by receiving deposits and trust funds from groups of individuals and redistributing those monies to eligible investors. However, the Jordanian economy is small, and there is fierce competition among Jordanian banks. It has compelled managers to improve their human resources practices and competencies to adapt to various environmental issues and integrate strategic Human Resources activities with business strategy.

Standard and operational HR procedures at the base level have proven insufficient to compete in a given market or sector and maintain a sustained competitive edge (Collins \& Clark, 2003). As a result, the requirement for the next level of HR procedures arises. (HR practices) are the effective means through which businesses can influence and shape workers' job abilities, attitudes, and performance to achieve organizational goals (Chen \& Huang, 2009).

The relationship between HR practices and organizational outcomes such as productivity, flexibility, and financial performance has received much attention in the literature. The impact of SHRM (Strategic HR Management) on employee engagement will be the subject of this study. Employee engagement is defined as a productive, satisfying, involved, and motivated state of mind at work (Khodakaram et al., 2018). The importance of human capital, on the other hand, raises the question of whether we should engage in allpurpose human capital, which includes coaching, education, and "off-the-job training," or firm-specific human capital development, which focuses on "on-the-job training" (Osei et al., 2019).

\section{THEORETICAL FRAMEWORK}

\section{A. Strategic Human Resource Practices}

Human resource management (HRM) refers to the procedures and regulations that govern employee behavior and performance. As evidenced by the literature, there is still no consensus on the definition of HRM (Boon et al., 2018). Nonetheless, human resource management (HRM) is a relatively new discipline that has experienced remarkable growth and development. Some authors have stressed the effectiveness of HR departments, while others have focused on HRM in terms of skills, knowledge, and talents (Zehir et al., 2016). They have focused on a few key activities that can affect organizational success, such as HR recruiting, selection, training and development, compensation, performance management, and employee relations (Zehir et al., 2016).

Yong and Mohd-Yusoff (2016) HRM practices are (1) Hiring new employees with care. (2) Teams that are selfmanaged, (3) Stability of employment, (4) Decision-making decentralization, (5) the fundamentals of organizational design, (6) Extensive training is required.

Significant contributions to the academic literature dealing with difficulties connected to people management have been extensively recognized in the previous few decades. HRM has gotten much attention as a new way of monitoring employees that is both effective and efficient. Nonetheless, the HRM research has been criticized as being "microanalytic" because it focused on specific issues and their effects on businesses. Researchers have generated new generations of theoretical and practical work linking HRM with business and corporate strategy during the previous decade (Boon et al., 2018).

Researchers in the subject has recently acquired an interest in SHRM. Despite the increased attention and consideration given to SHRM, the notions remain ambiguous and unclear to some extent. "The pattern of planned HR deployments and activities intended to enable the organization to achieve its goals," according to SHRM (Yong \& Mohd-Yusoff, 2016). SHRM is also defined as "organizational systems that use people to gain long-term competitive advantage." As a result, SHRM is the process by which HR practices and business strategy are linked (Yong \& Mohd-Yusoff, 2016).

Regardless of the lack of a specific definition for SHRM, its core concept is connecting and integrating HR operations with the organization's strategic direction to improve organizational performance and gain a sustainable competitive advantage (Al-Sarayrah et al., 2016). Furthermore, many researchers have criticized the SHRM basis theory and have advocated for new development (Yong \& Mohd-Yusoff, 2016).

\section{B. Employees Engagement}

In a scientific study, the explanation of HRM and employee engagement are debated. The importance of HRM in measuring employee performance and managing human capital is highlighted in this literature (Al-Dmour, 2020; Winasis et al., 2020). Adding value to customers and acting differently than competitors is a crucial differentiating component in making a plan successful (Al-Dmour, 2020). Employee engagement is a broad topic in HR that necessitates explanations. Many theories have been developed to describe employee engagement based on motivation theories, and it appears that it is necessary to reveal those theories to understand better the concept of employee engagement (Winasis et al., 2020).

The level of employee involvement has an impact. Employees' primary motivation has long been thought to be high pay (Bhardwaj et al., 2020); nevertheless, scholars have recently revealed that job features in general, not just pay, impact employee engagement. Employee engagement and performance are linked to the social environment and job characteristics - the emotional component of work that influences motivation. pyramid depicts the whole range of individual requirements, and he adds to Mayo's method by stating that human beings seek something other than money 
at work. As a result, work features impact employee engagement and attitude (Bhardwaj et al., 2020).

\section{Transformational Leadership}

Leadership is a broad term with numerous definitions. There are numerous definitions of leadership in management. Individual leadership, the relationship between leader and followers, and the impact of leadership on clients and external stakeholders differ depending on the company's level (Batistič et al., 2017). This type of leadership is defined as "the process of influencing the activities of an organized group in its efforts to identify and achieve goals." Furthermore, this leadership style is the art of persuading individuals to perform at their best to attain any given goal. Furthermore, leadership has various outcomes (Boamah et al., 2018). Batistič et al. (2017) pointed out that leadership outcomes can have an impact on a variety of levels, including the individual level (individual satisfaction, individual, organizational commitment), the immediate environment in which they operate (team interaction), and, in the long run, the overall organization's performance.

On the other hand, there are numerous definitions for organizational vision. Previously, the concept of "organizational vision" was defined as a cultural ideal that describes the principles that allow organizational operations to operate smoothly. These functions, in turn, lead to the survival of the organization. The vision is part of a highly innovative organizational culture that emphasizes each individual's contribution to the company's success. The goal is not to have a clear vision; instead, principals must act as visionary leaders to make it a reality (Boamah et al., 2018).

\section{LITERATURE REVIEW}

Employee's engagement, strategic HR, transformational leadership, and human capital are the most attractive topics that have resulted in many research publications in Arab countries. For example, Al-Dmour (2020) studied the employee's engagement mediating role in the association between the HR information system (HRIS) and employee's performance based on the social exchange theory. The study population entails the workers in the 21 five-star hotels in Jordan. Also, its administration a quantitative to a simple random sampling of $221 \mathrm{HR}$ specialists working at five-star hotels in Jordan. The study applied structural equation modelling (SEM) and factor analysis for data analysis purposes. The findings revealed that the HRIS had a significant favorable influence on both employee performance and engagement. Still, the engagement has a partial mediator role between HRIS and employee performance.

The study of Alneyadi et al. (2019) examine the relationship between the organizational culture, transformational leadership (independent construct) and human capital. The study population entails the workers in the public sector in the UAE. Transformational leadership is operationalized as the idealized influence, inspirational motivation, intellectual stimulation, and individualized consideration. Further, human capital is operationalized as skills. Last, the organizational culture is treated as a moderating variable. The study employs structural equation modelling (SEM) to analyze data from 307 questionnaires for the data analysis.

The study results demonstrated that transformational leadership has a significant impact on human capital. Additionally, it has a significant moderating role between transformational leadership and human capital.

Ram and Prabhakar (2011) analyzed the skills and consequences of employee engagement in the Jordanian industry from the Jordanian context. For the methodology, they applied a snowball sample of 310 workers from all managerial and non-managerial levels. They applied the interviews as a research instrument in Jordanian Industry. The study results indicate that there is a positive relationship between employee engagement and perceived organizational support. Further, the analysis proved the impact of job characteristics, intrinsic and extrinsic rewards, perceived supervisor support, perceptions of procedural justice, perceptions of distributive justice on employee engagement.

Besieux et al. (2018) examines the relationship between leadership and engagement in-depth. Also, it examines corporate social responsibility as a mediator variable. The study applied a questionnaire administered to a sample of 540 employees who work in 15 Islamic and commercial banks' headquarters. The study sample entailed 5313 employees who work in European banks. The results show that transformational leadership effectiveness impacts employee engagement, impacting corporate social responsibility as a mediator in this relationship. In the same content, Madanat and Khasawneh (2017) examined the impact of the total quality management ((customer focus, top management commitment, and continuous improvement) on the effectiveness of HR system (planning, staffing, training \& development, and performance appraisal) in the Jordanian banking sector. The results show that TQM impacts HRM effectiveness further, then indicates that there are no significant variations in the HR effectiveness to control factors of gender, experience, age, education, and job title in the Islamic and commercial banks.

Khan et al. (2018) studied transformational leadership and knowledge management on human capital effectiveness. The study applied the mixed research method for the methodology as the data is collected using a self-administrated questionnaire and semi-structured interviews. The SEM is also applied for the data analysis using AMOS and Nvivo software. The study findings showed that transformational leadership has a positive impact on KM strategies. Further, this study also identified that knowledge codification strategy and personalization strategy positively impact human capital effectiveness.

Prochazka et al. (2017) examine the self-efficacy mediating role in the relationship between the transformational leadership style and employee engagement. The study sample involved 307 Czech employees. The study results show that self-efficacy partially mediates the relationship between transformational leadership and engagement. However, it shows that the association between transformational leadership and workers' self-efficacy is weak, and the relationship between self-efficacy and engagement is moderately strong. The results also directly 
impact transformational leadership on the worker's engagement, and this relationship is strong.

The study of Mozammel and Haan (2016) examine the association between transformational leadership, commitment, and engagement in the banks in Bangladesh. The study findings indicate that the transformational leadership's work environment will not assure better employees' engagement. In contrast, Breevaart et al. (2016), who studies the transformational leadership behaviors and employee self-leadership strategies, support the levels of the engagement and then the job performance over a sample of 57 unique leader-employee dyads filled out a quantitative tool. The results of multilevel structural equation modelling showed that employees were more engaged in their work and received higher performance ratings from their leaders when leaders used more transformational leadership behaviors.

This study's distinction is based on investigating the mediating role of transformational leadership and the moderating role of the human capital on the impact of strategic HR and the employees' engagement. The model itself distinctive from the study as it integrates two models from the past literature. Further, the study covers the Jordanian banking sector at the end of 2020, where there are significant changes in management styles.

\section{STUdy METHOdS}

\section{A. Research Population}

The research population consists of all the 13 Jordanian commercial banks, as per the website for the Association of Banks in Jordan (Association of Banks in Jordan, 2020). The number of workers in the banks is estimated at 15,553. The researcher will use the proportional stratified random sample technique. According to the population size $(15,553)$ divided on the selected banks and depending on Sekaran`s table (Sekaran \& Bougie, 2016, 263), the sample size was determined based on the employees number in each selected bank with an acceptable margin of error $5 \%$. The sample size is 375 . The unit of analysis in this study will be the employee working in Jordanian commercial banks.

\section{B. Data Collection Methods}

This study will adopt a descriptive-analytical design. This methodology is appropriate for the phenomena under study. This research is trying to understand the elements of the phenomena by collecting the required data from the respondents associated with the phenomena. This study will depend on two sources for collecting data. The primary sources include the research instrument, which is based on a questionnaire to address the analytical aspects of the study. The questionnaire will consist of a few statements that will reflect the research objectives and dimensions and will cover the independent variable (Strategic Human resources activities and its dimensions) and the dependent variable (employee engagement and its dimensions, the questionnaire will be distributed on a sample of employees in Jordanian commercial banks, and it was prepared based on previous studies related to the topic. The researcher collects secondary data from secondary sources, including books, previous studies, published journal articles, master and doctoral theses in various universities and some Jordanian governmental agencies websites.

\section{Measurement Instruments}

The measurement instruments were adopted from previous literature to affirm the validity and reliability of the scales. The study will contain three main parts as the following:

- Part (1): The Demographic data includes the gender, scientific qualification, age, position, and years of experience of the respondent.

- Part (2): The measurement scale of transformational leadership was adopted based on the study of Sandell, (2012).

- Part (3): The measurement scale of SHRM was adopted based on the study of Darwish, (2012).

- Part (4): The measurement scale of employees' engagement was adopted based on the study of Weston, (2016).

- $\quad$ Part (5): The measurement scale of human capital was adopted based on the study of Dahiyat, (2015).

The questionnaire will be transcribed in English and then interpreted into Arabic to widen the segment of respondents. All items were rated as a five-point Likert scale as follows for positive questions: (5) = very important, (4) = Important, (3) = for Neither Important nor Unimportant, (2) = Unimportant, (1) = Very Unimportant

\section{Research Hypotheses}

According to the context of this research, below is the research hypothesis.

$\mathrm{HO}_{1}$ : There is no statistically significant impact at $\mathrm{p} \leq 5 \%$ of Strategic HR Practices and its dimensions (Staffing, Training, Participation, Appraising, and compensating) on employee engagement and its dimensions (Cognitive engagement, Emotional engagement, Behavioral engagement) in Jordanian Commercial Banks.

H02: There is no statistically mediating role at $\mathrm{p} \leq 5 \%$ of Transformational leadership on improving the impact of Strategic HR Practices and its dimensions (Staffing, Training, Participation, Appraising, and compensating) on employee engagement with its combined dimensions (Cognitive engagement, Emotional engagement, Behavioral engagement) in Jordanian Commercial Banks.

\section{E. Research Model}

In light of the research hypothesis, Fig. 1 illustrates the research model.

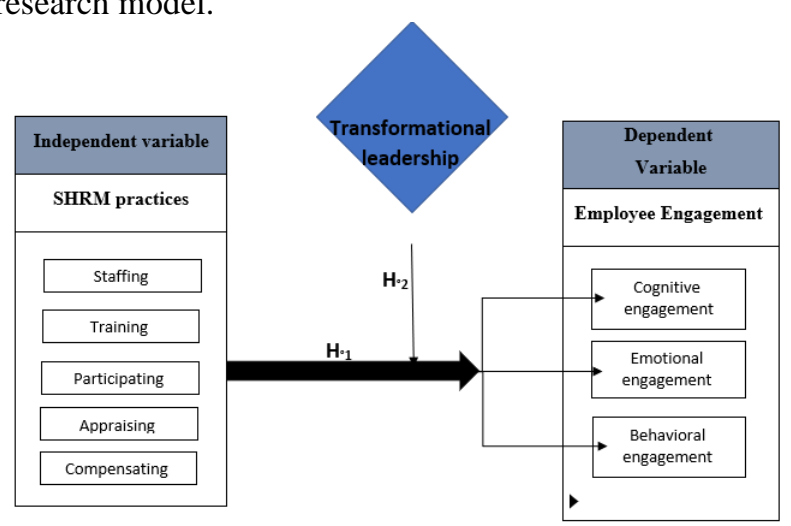

Fig. 1. The impact of Strategic HR practices on employee's engagement in Jordan Commercial banks (Shuck et al., 2014; Chen \& Huang, 2009; Le et al., 2018; Dahiyat, 2015) 


\section{DATA ANALYSiS}

Employees, managers, and senior managers specialized in the study area from the banking sector in Jordan. Out of the sample, 141 responses are obtained. The demographic features of the sample are shown in Table I.

\begin{tabular}{cccc}
\multicolumn{4}{c}{ TABLE I: DEMOGRAPHICS } \\
\hline Variable & Category & Counts & $\%$ \\
\hline \multirow{2}{*}{ Gender } & Females & 60 & $42.4 \%$ \\
& Males & 81 & $57.6 \%$ \\
& $1-5$ years & 15 & $11.5 \%$ \\
Experience & 6-10 years & 76 & $53.8 \%$ \\
& $11-15$ years & 32 & $23.0 \%$ \\
& 16-20 years & 13 & $09.3 \%$ \\
& More than 20 years & 5 & $02.4 \%$ \\
& Employees & 65 & $45.5 \%$ \\
& First level & 40 & $29.0 \%$ \\
& Second level & 28 & $19.2 \%$ \\
& manager & & \\
& Executive level & 10 & $07.1 \%$ \\
\hline
\end{tabular}

\section{A. Research Instrument}

The research questionnaire was created using a literature review and a pilot test before being distributed in its entirety, which included a cover letter and a definition that defined the study's objectives. To make the questionnaire more understandable, it was separated into sections and translated into Arabic. The first section is devoted to eliciting information about the sample demography (gender, position, and years of experience). The second half includes a fivepoint Likert scale ranging from one (strongly disagree) to five (strongly agree) to recognize the factors.

\section{B. Confirmatory Factor Analysis (CFA)}

AMOS 23 software was used to test confirmatory factor analysis (CFA). For items on its latent variables, it gives both standardized and unstandardized factor loading. AMOS has the advantage of providing indications for the study's overall data/goodness models of fit. There are numerous indicators available. The GFI, chi-square test (2), comparative fit index $\mathrm{CFI}$, the (2/df), the goodness of fit index, and the root mean square error approximate RMESA will all be used in this study. Each of these indicators has a reference cutoff value that corresponds to a model fit. The 2 test is an inferential test that employs probability to accept or reject the goodness of fit; the ideal condition is for the probability to be greater than 0.05 , indicating no statistical deviations between the actual measured model and the theoretical model. The fact that two is sensitive to sample size is one of its drawbacks. As a result, researchers rarely get an excellent chi-square value ( $p>0.05)$. In the same context, the RMSEA refers to the average of squared errors; the lower the number, the more likely the common condition would be satisfied; usually, a value of less than 0.08 is considered a favorable signal. The GFI and CFI readings are both in the range of (0-1). A value of 0.90 or higher indicates that the model is well-fitting. If the obtained result was (3), the $2 / \mathrm{df}$ indicator is considered a good indicator. Convergent Validity and Reliability Analysis Results Composite (CR) and Cronbach Alpha (CA) utilizing Confirmatory Factor Analysis (CFA) are summarized in Table II).

TABLE II: DEMOGRAPHICS

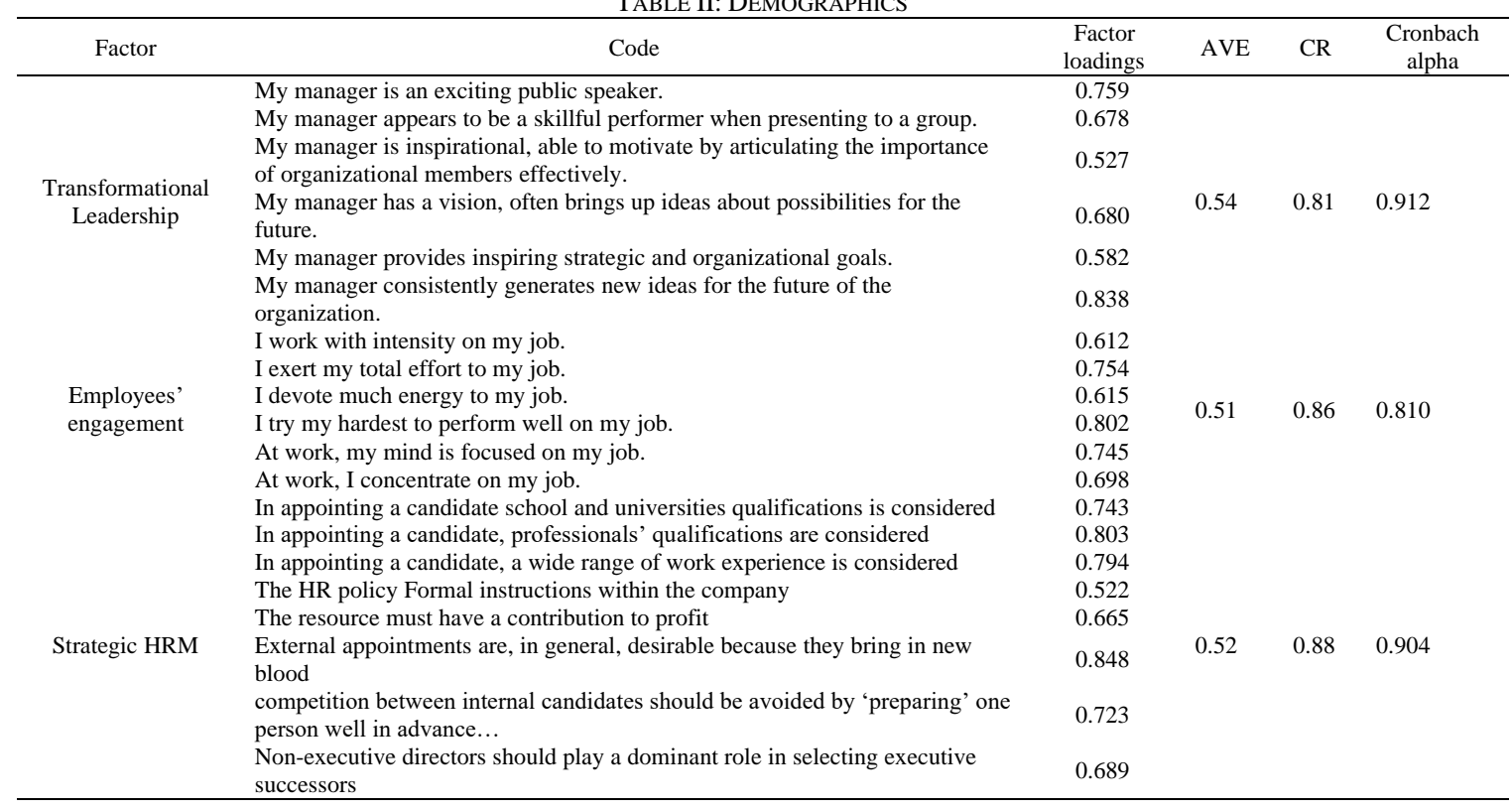

The factor loadings result in table ( II ) exhibit convergent validity based on the CFA analysis. In the performance factor, the minor factor loading was "The HR policy Formal instructions within the company", as seen in the findings (0.522). This figure, however, is greater than the recognized cutoff limit of 0.40 , indicating that the components have reasonable convergent validity. As a result, the convergent validity is determined based on the values. The AVE represents the number of variations among the items of the latent variable. As a good indication of factor validity, this indicator value must be greater than 0.50 . This is because it was checking the provided values. It was also clear that the minimal value for knowledge exchange was (0.506). As a result, the findings indicate that the factors' validity has been established. The results of the composite and Cronbach alpha reliabilities are listed in Table $\Pi$. The provided reliability values reflect good reliability values $(>0.50)$. Hence a conclusion of high reliability might be drawn. 


\section{Results of Testing the Main Hypothesis}

The impact of HRM on employee commitment is stated by the standardized beta coefficient, based on the fallouts provided by table (IV). (0.972). With a probability value of 0.001 , this impact value is statistically significant. As a result, the main hypothesis, which represents the null hypothesis, is rejected, indicating that HRM impacts employee commitment.

The standardized beta coefficient (0.630) represents the influence of transformative leadership on employee commitment; this impact value was statistically significant because the corresponding probability value was 0.001 . Because the associated probability value was 0.05 (actually 0.001), the impact value of HRM on transformational leadership was declared statistically significant.

The VAF (variance accounted for) number ( 24.6 per cent) in the same frame suggests that the indirect effect to the total effect implies that the mediation is numerically partially too. The effect is called a "complementary partial effect" when the impact indications of a mediator's two routes are positive. As a result, at $\operatorname{sig}=0.05$, the null hypothesis of a mediating role is rejected.

\begin{tabular}{ccccccc}
\multicolumn{7}{c}{ TABLE III: MODEL FITTING INDICATORS } \\
\hline \multicolumn{1}{c}{$\chi^{2}$} & $\mathrm{p}$ & $\chi 2 / \mathrm{df}$ & GFI & CFI & RMSEA \\
\hline $\begin{array}{c}\text { Indicator } \\
\text { critical }\end{array}$ & 3.12 & 0.682 & 0.625 & 0.93 & 0.95 & 0.007 \\
values & 0.00 & 1.00 & 4.00 & $\begin{array}{c}(90- \\
100 \%)\end{array}$ & $\begin{array}{c}(90- \\
100 \%)\end{array}$ & $\begin{array}{c}0.00- \\
0.08)\end{array}$ \\
\hline
\end{tabular}

According to Table III the chi-square value (3.12) is not statistically significant because the corresponding probability value $(0.682)$ is greater than $5 \%$, implying no statistically significant differences. Furthermore, the " $2 / \mathrm{df}$ " indicator had a value of $(0.625)$, which was greater than the cutoff point, and the goodness of fit index GFI and CFI had values of 0.93 and 0.95 , respectively, which were acceptable because they were above the critical value (0.90). Finally, the RMSEA value was (0.010), indicating that the fit was good and acceptable because the value was less than 0.08 . As a result, the indices indicate that the model is well-fitting.

\section{CONCLUSIONS}

Standard and operational HR procedures at the base level have proven insufficient to compete in a given market or sector and maintain a sustained competitive edge. As a result, the need for the next level of HR arises. (HR practices) are the primary means by which businesses can influence and shape employees' work skills, attitudes, and performance to achieve organizational goals.

The relationship between HR practices and organizational outcomes such as productivity, flexibility, and financial performance has received much attention in the literature. The impact of SHRM (Strategic HR Management) on employee engagement will be the subject of this study. Employee engagement is defined as a productive, satisfying, involved, and motivated state of mind at work (Khodakarami et al., 2018). The importance of human capital, on the other hand, raises the question of whether we should engage in allpurpose human capital, which includes coaching, education, and "off-the-job training," or firm-specific human capital development, which focuses on "on-the-job training." (Osei et al., 2019). Because transformative leadership has an impact on staff creativity and performance.

The hypotheses related to the impact of the independent variable on the dependent variable

\begin{tabular}{cccccc}
\multicolumn{5}{c}{ TABLE IV: STANDARDIZED - TOTAL EFFECTS } \\
\hline Hypotheses & \multicolumn{3}{c}{ Impact Direction } & $\beta$ & prob \\
\hline $\mathrm{H}_{1}$ & $\mathrm{HRM}$ & $-->$ & $\begin{array}{c}\text { Employees' } \\
\text { commitment }\end{array}$ & 0.972 & $* * *$ \\
$\mathrm{HO}_{2}$ & $\begin{array}{c}\text { Transforma- } \\
\text { tional } \\
\text { leadership }\end{array}$ & $-->$ & $\begin{array}{c}\text { Employees' } \\
\text { commitment }\end{array}$ & 0.630 & $* * *$ \\
$\mathrm{HO}_{3}$ & $\mathrm{HRM}$ & $--->$ & $\begin{array}{c}\text { Transformational } \\
\text { leadership }\end{array}$ & 0.615 & $* * *$ \\
\hline
\end{tabular}

Note. Indicate that the prob value is $<0.001)$.

This study investigates the impact of HRM on employee commitment and the mediating role of transformational leadership. The study population entails all managers and employees in Jordanian banks. The sample size is 375 , and the valid response is 131 respondents. The study results confirm the impact of HRM on employees' commitment and the partial mediating role of transformational leadership.

\section{RECOMMENDATIONS}

This study recommends that future researchers extend the study to other industrial and service sectors. Further, It is recommended to study other leadership styles such as the distributed leadership. The impact of COVID 19 needs to be investigated as the transformation into an online working style changes the commitment of the employees and the role of HRM.

\section{REFERENCES}

Al-Dmour, R. H. (2020). The Influence of HRIS Usage on Employee Performance and Mediating Effects of Employee Engagement in Five Stars Hotels in Jordan. International Journal of Information Systems in the Service Sector (IJISSS), IGI Global, 12(3), 1-18.

Alneyadi, B. A., Al-Shibami, A. H., Ameen, A., \& Bhaumik, A. (2019). Moderating Effect of Organizational Culture on Relationship between Transformational Leadership and Human Capital: An Empirical Study on Public Sector of UAE. International Journal on Emerging Technologies, 10, 23-31.

Al-Sarayrah, S., Tarhini, A., Obeidat, B. Y., Al-Salti, Z., \& Kattoua, T. (2016). The effect of culture on strategic human resource management practices: A theoretical perspective. International Journal of Business Management and Economic Research, 7(4), 704-716.

Alzyoud, A. A. Y. (2018). The influence of human resource management practices on employee work engagement. Foundations of Management, 10(1), 251-256.

Batistič, S., Černe, M., \& Vogel, B. (2017). Just how multi-level is leadership research? A document co-citation analysis 1980-2013 on leadership constructs and outcomes. The Leadership Quarterly, 28(1), 86-103.

Besieux, T., Baillien, E., Verbeke, A. L., \& Euwema, M. C. (2018). What goes around comes around: The mediation of corporate social responsibility in the relationship between transformational leadership and employee engagement. Economic and Industrial Democracy, 39(2), 249-271.

Bhardwaj, A., Mishra, S., \& Jain, T. K. (2020). Analysis of strategic leadership for organizational transformation and employee engagement. Materials Today: Proceedings, 37, 161-165.

Boamah, S. A., Laschinger, H. K. S., Wong, C., \& Clarke, S. (2018). Effect of transformational leadership on job satisfaction and patient safety outcomes. Nursing Outlook, 66(2), 180-189.

Boon, C., Eckardt, R., Lepak, D. P., \& Boselie, P. (2018). Integrating strategic human capital and strategic human resource management. The International Journal of Human Resource Management, 29(1), 34-67.

Breevaart, K., Bakker, A. B., Demerouti, E., \& Derks, D. (2016). Who takes the lead? A multi-source diary study on leadership, work engagement, 
and job performance. Journal of Organizational Behavior, 37(3), 309 325.

Chaudhry, S., \& Joshi, C. (2017). Transformational leadership, HR practices and affective commitment to change: A theoretical perspective. Journal of Organisation and Human Behavior, 6(3), 37-45.

Chen, C. J., \& Huang, J. W. (2009). Strategic human resource practices and innovation performance - The mediating role of knowledge management capacity. Journal of Business Research, 62(1), 104-114.

Collins, C. J., \& Clark, K. D. (2003). Strategic human resource practices, top management team social networks, and firm performance: The role of human resource practices in creating organizational competitive advantage. Academy of Management Journal, 46(6), 740-751.

Dahiyat, S. E. (2015). An integrated model of knowledge acquisition and innovation: Examining the mediation effects of knowledge integration and knowledge application. International Journal of Learning and change, 8(2), 101-135.

Danish, R. Q., Holbrook, A., Latif, Y., Shaukat, \& Shaheen, U. (2016). Impact of intellectual capital on organizational creativity through technical innovation in telecom sector sizes. Journal of Statistics, 23(1), 17-31.

Darwish, T. K. (2012). Strategic human resource management and organizational performance: An investigation in the country of Jordan. [Doctoral dissertation], Brunel University London.

Engelman, R. M., Fracasso, E. M., Schmidt, S., \& Zen, A. C. (2017). Intellectual capital, absorptive capacity and product innovation. Management Decision, 55(3), 474-490.

Guthrie, J., Dumay, J., \& Puntillo, P. (2015). IC and public sector: A structured literature review. Journal of Intellectual Capital, 16(2), 267284.

Khan, M. S., Sentosa, I., \& Salman, F. (2018). Exploring the role of transformational leadership in human capital effectiveness. World Journal of Entrepreneurship, Management and Sustainable Development, 14(2), 191-204.

Khodakarami, N., Dirani, K., \& Rezaei, F. (2018). Employee engagement: finding a generally accepted measurement scale. Industrial and Commercial Training, 50(6), 305-3011.

Lamond, D., \& Zheng, C. (2010). HRM research in China: Looking back and looking forward. Journal of Chinese Human Resources Management, $1(1), 6-16$

Le, B. P., Lei, H., Phouvong, S., Than, T. S., Nguyen, T. M. A., \& Gong, J. (2018). Self-efficacy and optimism mediate the relationship between transformational leadership and knowledge sharing. Social Behavior and Personality: An International Journal, 46(11), 1833-1846.

Loshali, S., \& Krishnan, V. R. (2013). Strategic human resource management and firm performance: Mediating role of transformational leadership. Journal of Strategic Human Resource Management, 2(1), 9.

Madanat, H. G., \& Khasawneh, A. S. (2017). Impact of total quality management implementation on effectiveness of human resource management in the Jordanian banking sector from employees' perspective. Academy of Strategic Management Journal, 16(1).

Mahmood, M., Uddin, M. A., \& Fan, L. (2019). The influence of transformational leadership on employees' creative process engagement: A multi-level analysis. Management Decision, 57(3), 741-764.

Mozammel, S., \& Haan, P. (2016). Transformational leadership and employee engagement in the banking sector in Bangladesh. The Journal of Developing Areas, 50(6), 43-55.

Oluwatayo, A. A., \& Adetoro, O. (2020). Influence of employee attributes, work context and human resource management practices on employee job engagement. Global Journal of Flexible Systems Management, 21(4), 295-308.

Osei, H. V., Agyapong, A., \& Kwateng, K. O. (2019). The moderated mediation processes in firm-specific human capital development and task performance relationship. International Journal of Organizational Analysis, 27(3), 396-413.

Preko, A. (2014). Assessing the impact of human capital development on effective work performance at selected departments in the College of Arts and Social Sciences. [Doctoral dissertation], Kwame Nkrumah University of Science and Technology.

Prochazka, J., Gilova, H., \& Vaculik, M. (2017). The relationship between transformational leadership and engagement: Self-efficacy as a mediator. Journal of Leadership Studies, 11(2), 22-33.

Pulic, A. (1998, January). Measuring the performance of intellectual potential in knowledge economy. In 2nd McMaster Word Congress on Measuring and Managing Intellectual Capital by the Austrian Team for Intellectual Potential (pp. 1-20).

Raina, B., \& Kalse, A. (2018). A study of human resource practices on employee work engagement in hospitality industry. BVIMSR's Journal of Management Research, 10(2), 194-206.

Ram, P., \& Prabhakar, G. V. (2011). An enquiry into the mediatory role of employee engagement: Evidence from the hotel industry in Jordan. Far East Journal of Psychology and Business, 5(2), 41-59.

Sandell, K. (2012). Transformational leadership, engagement, and performance: A new perspective. [Doctoral dissertation], Colorado State University.

Sekaran, U., \& Bougie, R. (2016). Research methods for business: A skill building approach. John Wiley \& Sons.

Shuck, B., Twyford, D., Reio Jr, T. G., \& Shuck, A. (2014). Human resource development practices and employee engagement: Examining the connection with employee turnover intentions. Human Resource Development Quarterly, 25(2), 239-270.

Singh, S. K., Del Giudice, M., Chierici, R., \& Graziano, D. (2020). Green innovation and environmental performance: The role of green transformational leadership and green human resource management. Technological Forecasting and Social Change, 150, 119762.

Teece, D. J. (2007). Explicating dynamic capabilities: The nature and microfoundations of (sustainable) enterprise performance. Strategic Management Journal, 28(13), 1319-1350.

Weston, J. W. (2016). Employee engagement: Understanding the construct's stability. [Doctoral dissertation], Colorado State University.

Winasis, S., Djumarno, Riyanto, S., \& Ariyanto, E. (2020). Digital transformation in Indonesian banking industry: Impact on employee engagement. International Journal of Innovation, Creativity and Change, 12(4), 528-543.

Yong, J. Y., \& Mohd-Yusoff, Y. (2016). Studying the influence of strategic human resource competencies on the adoption of green human resource management practices. Industrial and Commercial Training, 48(8), 416-422.

Zehir, C., Gurol, Y., Karaboga, T., \& Kole, M. (2016). Strategic human resource management and firm performance: The mediating role of entrepreneurial orientation. Procedia-Social and Behavioral Sciences, $235,372-381$. 